\title{
ESTIMATIVAS DE POLINIZAÇÃO CRUZADA EM POPULAÇÃO DE Spondias tuberosa ARRUDA (ANACARDIACEAE) USANDO MARCADOR AFLP ${ }^{1}$
}

Carlos Antonio Fernandes Santos², Viseldo Ribeiro de Oliveira ${ }^{3}$, Marciene Amorim Rodrigues ${ }^{3}$, Hugo Leonardo Coelho Ribeiro ${ }^{4}$ e Marcos Antonio Drumond ${ }^{5}$

\begin{abstract}
RESUMO - O umbuzeiro é uma das espécies mais importantes do semiárido brasileiro, devido à sua capacidade de produzir frutos em ambiente de estresse hídrico. O objetivo deste estudo foi estimar taxas de polinização cruzada em umbuzeiro $(\mathfrak{t})$, considerando-se a frequência de heterozigotos observada e esperada nas populações maternal e de descendentes (M1), respectivamente, e a estimativa de multilocos (M2), de forma a orientar programas de preservação e melhoramento genético da espécie. Amostras de DNA extraído de uma população maternal de 96 plantas, estabelecidas no campo em 1991, em Petrolina, PE, bem como DNA de um indivíduo descendente de cada planta-mãe, foram analisadas para 16 bandas polimórficas das combinações de primer de AFLPAAA_CTG e AAA_CTC. No M1, considerou-se a frequência de heterozigotos estimada pela raiz quadrada de 1 menos a frequência de ausência de fragmentos AFLP, tanto para a população maternal (frequência observada) quanto para a população de descendentes (frequência esperada), enquanto no M2 a estimativa foi obtida por estimativa multilocos $\left(\widehat{\mathfrak{t}}_{\mathrm{m}}\right)$. As estimativas de $\widehat{\mathrm{t}}$ no $\mathrm{M} 1$ variaram de 1,74 a 0,50 , com média de 1,063. Como valores de t acima de 1,0 são biologicamente inaceitáveis, ficou demonstrado que M1 não foi apropriado para estimar t. As frequências de óvulos e pólen para 15 locos de AFLP foram iguais, indicando boa adequação do modelo de acasalamento misto no M2. A taxa $\widehat{\mathfrak{t}}_{\mathrm{m}}$ obtida pelo M2 foi de 0,719, próxima de estimativas prévias com isoenzimas em outras populações da espécie. Os resultados indicam que o umbuzeiro é predominantemente de polinização cruzada e há necessidade de amostras amplas para preservar a variabilidade genética da espécie.

Palavras-chave: Taxa de cruzamento MLTR, Heterozigotos e Anacardiaceae.

\section{ESTIMATION OF OUT-CROSSING IN Spondias tuberosa Arruda (ANACARDIACEAE) POPULATION BY USING AFLP MARKER}

\begin{abstract}
Umbu tree is one of the most important species in the Brazilian semi-arid region due to its ability to produce fruit in water stress environments. The objective of this work was to estimate outcrossing rates in the $\boldsymbol{S}$. tuberosa $(\mathfrak{\mathrm { t }})$, by considering the observed and expected frequency of heterozygous in the mother and descent population (M1), respectively, and the estimate of multilocus (M2), to direct programs of conservation and genetic improvement of the species. Samples of DNA extracted from a maternal population with 96 plants established in 1991, at Petrolina, PE, as well as the DNA from one descent from each maternal plant were analyzed for the 16 polymorphic AFLP bands obtained from AAA_CTG and AAA_CTC primer combinations. In M1, it was considered the frequency of heterozygote estimated by the square root of 1 minus the AFLP fragment absence frequency, for the maternal population (observed frequency) and also for the descent population (expected frequency), whereas in the M2, the estimate was obtained by the multilocus estimate $\left(\widehat{\mathfrak{t}}_{m}\right)$. The $\hat{\mathrm{t}}$ estimates of $\mathrm{M} 1$ ranged from 1.74 to 0.50 , with mean value of 1.063 . Because values of $\hat{\mathrm{t}}$ above 1.0 are biologically inadequate, it was demonstrated that M1 was not appropriate to estimate $\hat{\mathrm{t}}$. Frequencies of pollen and ovule for 15 AFLP loci were the same, suggesting good adjustment to the mixed mating model in M2. The $\mathrm{t}$ rate obtained by M2 was 0.719 , which was close to previous estimates with isoenzymes obtained in other umbu tree populations. Results point that umbu tree is predominantly an outcrossing species and there is the need for broad samples in order to preserve the genetic variability of this species.
\end{abstract}

Keywords: Heterozygous, MLTR and Outcrossing rate.

\footnotetext{
${ }^{1}$ Recebido em 15.12.2008 e aceito para publicação em 18.04.2011.

2 Empresa Brasileira de Pesquisa Agropecuária, Embrapa, Brasil. E-mail: <casantos@cpatsa.embrapa.br>.

${ }^{3}$ Empresa Brasileira de Pesquisa Agropecuária, Embrapa, Brasil.E-mail: <viseldo@cpatsa.embrapa.br> e <eninharodrigues@hotmail.com>.

${ }^{4}$ Universidade Estadual de Feira de Santana, UEFS, Brasil. E-mail: <leonardokoelho@hotmail.com>.

${ }^{5}$ Empresa Brasileira de Pesquisa Agropecuária, Embrapa, Brasil. E-mail: <drumond@cpatsa.embrapa.br>.
} 


\section{INTRODUÇÃO}

O conhecimento do sistema de acasalamento é fundamental para programas de melhoramento genético e conservação de uma espécie, pois permite estabelecer estratégias que otimizem a amostragem da variabilidade genética, a adoção de modelos genético-estatístico apropriados para a estimativa de parâmetros genéticos, bem como para definição de estratégias para a conservação dessa espécie. As espécies podem produzir descendentes através de diferentes formas de acasalamento, como: cruzamento ao acaso, cruzamento associado, endogamia biparental, autofertilização, apomixia e combinações dos diferentes tipos. O sistema de acasalamento, juntamente com os mecanismos de dispersão de pólen e sementes, determina parte da estrutura genética da população (FREITAS et al., 2004).

Espécies resultantes de polinização cruzada mantêm a sua variabilidade genética distribuída dentro populações, em contraste com espécies de autofecundação que tem variabilidade genética distribuída entre populações (HAMRICK; GODT, 1989). Estudos do sistema de acasalamento de espécies tropicais têm demonstrado que a maioria das espécies são alógamas (polinização cruzada), ou possuem sistema mistos, com predominância da alogamia (FREITAS et al., 2004; GUSSON et al., 2006).

O desenvolvimento e aplicação de isoenzimas foram valiosos para estimar a taxa de polinização cruzada em populações de plantas. Mais recentemente, marcadores de DNA como RAPD e AFLP têm sido usados para estimar taxas de polinização cruzada (MULUVI et al., 2004; GAIOTTO et al., 1997). Apesar das limitações dos marcadores RAPD e AFLP, devido à sua dominância, Ritland (2002) demonstrou que essa limitação pode ser superada com estimação multilocos para alelos apresentando frequência intermediária. O AFLP é um marcador de DNA robusto que produz grande número de marcas de resolução especifica, devido à digestão com enzimas de restrição e à rápida detecção de polimorfismo por PCR (GAIOTTO et al., 1997), além de possibilitar ampla cobertura de um genoma.

O sistema de cruzamento do umbuzeiro foi avaliado com isoenzimas (SOUZA, 2000), mas não com marcadores codominantes, como microssatélites e com marcadores dominantes como AFLPe RAPD. Avaliação de marcadores microsatélites de Mangifera indica L. (Anacardiaceae) foi realizado em umbuzeiro, mas a transferibilidade não foi possível devido à ausência de amplificação para 30 primers testados (RIBEIRO et al., 2008).

O umbuzeiro (Spondias tuberosa Arruda Anacardiaceae) é uma espécie xerófita endêmica para a região do semiárido brasileiro (PRADO; GIBBS, 1993). A adaptação dessa espécie ao ambiente semiárido é conferida por um sistema especializado de raízes (xilopódio), que é importante para armazenar água e minerais. Os frutos do umbuzeiro apresentam características peculiares e são usados para consumo in natura ou processado em diversas formas. Por essas razões, a espécie é considerada espécie potencial para cultivo na região (SANTOS, 1999).

O objetivo deste estudo foi determinar o sistema reprodutivo de $S$. tuberosa, usando-se marcador AFLP e duas estimativas, uma tendo como referência a estimativa de multilocos disponíveis no software MLTR e outra considerando a frequência de heterozigotos observada e esperada nas mães e progênies, respectivamente, de forma a orientar programas de conservação e melhoramento genético da espécie.

\section{MATERIAL E MÉTODOS}

\subsection{Estratégia de amostragem e material genético}

Foram coletadas folhas e sementes de 96 indivíduos de umbuzeiro, que foram estabelecidos no campo em 1991, na Estação Experimental da Caatinga, da Embrapa Semiárido, Petrolina, PE. As sementes de cada indivíduo amostrado foram plantadas, coletando-se folhas de apenas uma plântula de cada descendente de cada uma das plantas- mães amostradas em campo. As folhas das plantas-mãe e dos descendentes foram armazenadas separadamente em freezer a $-80^{\circ} \mathrm{C}$ até a extração do DNA.

\subsection{Extração de DNA e reações de AFLP}

O DNA foi extraído das folhas segundo Doyle e Doyle (1990), modificado para: 6.000 e $10.000 \mathrm{rpm}$ na primeira e na segunda centrifugação, respectivamente; betamercaptoetanol $2 \%$ e incubação a $60{ }^{\circ} \mathrm{C}$, durante $30 \mathrm{~min}$ em todas as amostras. Após a adição do tampão Tris-EDTA, a solução de DNA foi tratada com RNAse para remover RNAs coisolados. A quantificação e integridade do DNA foram verificadas em gel de agarose, seguido da diluição do DNA genômico para $40 \mathrm{ng} \mu \mathrm{L}^{-1}$.

Revista Árvore, Viçosa-MG, v.35, n.3, Edição Especial, p.691-697, 2011 
Aproximadamente, 200 ng de DNA de cada material genético foi duplamente digerido por 2,5 h com 0,65 unidade das endonucleases EcoRI e MseI. Após a preamplificação, as amostras foram diluídas 20 vezes em tampão TE. Foram realizadas reações seletivas de amplificação para um volume final de $10 \mathrm{~mL}(0,2 \mu \mathrm{M}$ do primer da EcoRI, 0,3 $\mu \mathrm{M}$ do primer da MseI, 0,2 mM de dNTPs, $1 \mathrm{x}$ tampão de PCR (100 mM Tris-HCl (pH 8,3), $500 \mathrm{mM} \mathrm{KCl),} \mathrm{2,5} \mathrm{mM} \mathrm{de} \mathrm{MgCl}_{2}, 0,5$ unidade de Taq DNA Polimerase e $2 \mu \mathrm{L}$ do DNA preamplificado). A programação do termociclador para as amplificações seletivas consistiram de um ciclo de $94^{\circ} \mathrm{C}$, seguido de $65{ }^{\circ} \mathrm{C}$ durante 30 seg e de $72{ }^{\circ} \mathrm{C}$ durante 60 seg, repetidos 13 vezes e com a temperatura de anelamento de $65{ }^{\circ} \mathrm{C}$, diminuindo de $0,7{ }^{\circ} \mathrm{C}$ em todo o ciclo subsequente; 23 ciclos a $94{ }^{\circ} \mathrm{C}$ por $30 \mathrm{seg}, 56^{\circ} \mathrm{C}$ durante 30 seg e $72^{\circ} \mathrm{C}$ durante $1 \mathrm{~min}$. As reações foram aquecidas durante $3 \mathrm{~min}$ a $94{ }^{\circ} \mathrm{C}$, na presença de formamida e imediatamente colocadas sob o gelo antes da aplicação nos géis de poliacrilamida. Os géis foram corados com nitrato de prata, conforme Creste et al. (2001). Todas as reações foram conduzidas no Laboratório de Genética da Embrapa Semiárido.

\subsection{Análise estatística dos dados}

Bandas polimórficas de AFLP foram anotadas para presença (1) ou ausência (0). Foram efetuadas duas estimativas para a taxa de cruzamento.

Método 1: Estimativa da taxa de cruzamento tendo como referência a frequência de heterozigotos observada nas mães e frequência esperada nos descendentes de cada planta-mãe. Para cálculo de “q” (banda ausente ou 0), adotou-se a equação: $\mathrm{q}=\sqrt{\text { frequencia de zero }}$. "p" foi estimado por 1 - “q", e 2 pq foram estimados por $2^{*} p^{*} \mathrm{q}$. O coeficiente de endogamia foi estimado por: $\widehat{\mathrm{f}}=(\mathrm{He}-\hat{\mathrm{H}} \mathrm{o}) / \widehat{\mathrm{He}}$, em que He é a frequência esperada e Ĥo , a frequência observada dos heterozigotos nos descendeste e nas mães, respectivamente. A estimativa da taxa de cruzamento (“t”) foi obtida por: $\widehat{\mathfrak{t}}=(1-\widehat{f})+(1+\widehat{f})$ (PAIVA et al., 1994). As frequências das bandas “ 0 ” foram previamente submetidas ao teste de qui-quadrado, seja para segregação $3: 1$, 1:1 ou 1:3, para verificar desvios do equilíbrio de Hardy-Weinberg (PASTEUR et al., 1988).

Método 2: Estimativa multilocos, considerando o modelo de acasalamento misto disponível no programa MLTR(RITLAND, 2002). Os seguintes parâmetros foram estimados: taxa multilocos de cruzamento $\left(\widehat{\mathrm{t}}_{\mathrm{m}}\right)$, taxa uniloco de cruzamento $\left(\mathfrak{t}_{\mathrm{S}}\right)$, coeficiente médio de endogamia $(\widehat{F})$ e frequência de óvulos e pólen.

\section{RESULTADOS}

Foi obtido um total de 16 fragmentos polimórficos, sendo seis na combinação de primer (CP) AAA_CTG e 10 na CPAAA_CTC de AFLP, que foram consistentes nas duas populações: mães e progênies. Santos et al. (2008), trabalhando com umbuzeiro, anotaram de três a 16 bandas polimórficas por CP de AFLP, o que está de acordo com os resultados deste trabalho. Foram anotadas apenas as bandas bem definidas diretamente na placa de vidro, evitando-se bandas que apresentassem pequena diferença da posição no gel (Figura 1).

\subsection{Estimativa da taxa de cruzamento considerando a frequência de heterozigotos observada (mães) e a esperada (progênies): Método 1}

Entre as 16 marcas polimórficas de AFLP, foram anotadas cinco bandas, quais sejam: AAA_CTG_1, AAA_CTG_2, AAA_CTC_3, AAA_CTC_5 e AAA_CTC_6, que apresentaram desvio de herança mendeliana nas segregações de 3:1, 1:1 ou 1:3 pelo teste do qui-quadrado a $5 \%$ de probabilidade (Tabela 1) e

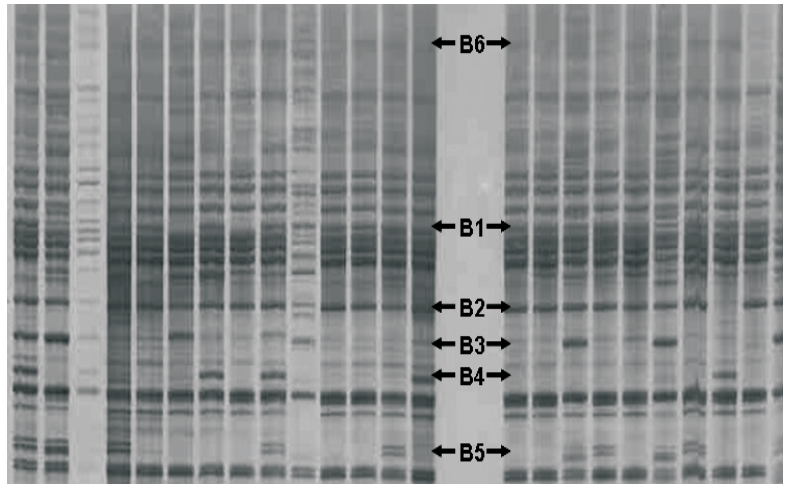

Figura 1 - Padrão representativo de seis bandas de AFLP da combinação de primers AAA_CTG em 14 indivíduos na população de progênies (esquerda) e 13 indivíduos na população materna (direita) analisadas para determinar o sistema de acasalamento em umbuzeiro. Petrolina, PE, 2008.

Figure 1 -Representative pattern of six AFLP bands of the primer combination AAA_CTG in 14 progenies population (left) and 13 maternal plants (right) analyzed to estimate the mating system of umbu tree. Petrolina, PE, 2008. 
não foram usadas para estimar a taxa de acasalamento pelo método 1. As estimativas de “q” apresentaram diferenças que variaram de -0,196 a 0,236 entre a população materna e a população de progênies, indicando que a população apresentava variação para “q” e por consequência para “p”e "2pq" (Tabela 1).

A heterozigose observada e esperada variou de 0,147 a 0,499 e de 0,211 a 0,500 , respectivamente (Tabela 2). O máximo que a frequência de heterozigotos pode alcançar é de 0,50 (FALCONER; MACKAY, 1996), e foi observada no fragmento de AFLPAAA_CTC_10 (Tabela 2). O coeficiente de endogamia ou índice de fixação de Wright ( $\widehat{F}$ ) variou de -0,271 a 0,331 (Tabela 2). Valores negativos de $\widehat{F}$ indicam excesso de heterozigotos na população e alogamia acentuada como destacado por Ruvolo-Takasusuki et al. (2002) e Giudice Neto et al. (2005). As estimativas da taxa de cruzamento $(\widehat{\mathrm{t}})$ para o Método 1 variaram de 1,74 a 0,50, e os maiores e menores valores de estiveram associados com os menores e maiores valores de, respectivamente (Tabela 2). Paiva et al. (1994), trabalhando com esses mesmos estimadores em seringueira, encontraram apenas valor ligeiramente superior a 1,0 entre quatro sistemas isoenzimáticos. A média geral para, considerando os 11 fragmentos de AFLP, foi de 1,063 (Tabela 2). Essa estimativa, tendo como referência o coeficiente de endogamia de Wright, está em desacordo com a estimativa obtida por Souza (2000), que estimou a taxa aparente de cruzamento em 0,74 , usando três sistemas de isoenzimas e estimadores de componentes de variância.

\subsection{Estimativas multilocos, considerando o modelo de acasalamento misto disponível no programa MLTR : Método 2}

As frequências de óvulos e pólen em 15 locos de AFLP (Tabela 1) foram iguais, indicando que não houve violação do modelo de acasalamento misto, necessário para a correta estimação da taxa de cruzamento multilocos, como proposto por Ritland (2002). A taxa de cruzamento multilocos $\left(\widehat{\mathfrak{t}}_{\mathrm{m}}\right)$ foi de 0,719 ( $\left.\pm 0,000\right)$, enquanto a taxa de cruzamento uniloco $\left(\widehat{\mathrm{t}}_{\mathrm{S}}\right)$ foi de 0,713 ( \pm 0,001), indicando que $S$. tuberosa Arruda é predominantemente de polinização cruzada, com taxa de autofecundação de 0,287. A estimativa multilocos de 0,713 é próxima do valor estimado por Souza (2000) em S. tuberosa.
A diferença entre $\widehat{t}_{\mathrm{m}}$ e $\widehat{\mathrm{t}}_{\mathrm{S}}$ foi de $0,007( \pm 0,000)$, sugerindo que a endogamia biparental (endogamia resultante do acasalamento entre parentes) foi praticamente inexistente. O coeficiente médio de endogamia ou índice de fixação das árvores maternas (F) foi de $-0,200( \pm 0,000)$, enquanto esperada era de 0,163 , assumindo que $\widehat{\mathrm{F}}$ esperado é dado por $\widehat{\mathrm{F}}=\left(1-\widehat{\mathrm{t}}_{\mathrm{m}}\right) /\left(1+\widehat{\mathrm{t}}_{\mathrm{m}}\right)$ (GAIOTTO et al., 1997), indicando que existiu excesso de heterozigotos e endogamia menor na população materna estudada. Excesso de heterozigotos foi também reportado por Moraes et al. (2005) em Myracrodruon urundeuva Engl. (Anacardiaceae), com valores variando de $-0,252$ a 0,511 .

\section{DISCUSSÃO}

Modelos genético-estatísticos quase sempre estão condicionados às pressuposições para a correta estimativa dos parâmetros diversos. O modelo de estimativa multilocos (RITLAND, 2002) assume algumas pressuposições básicas, como revisado por Sebbenn et al. (1998): (1) que o conjunto de pólen é homogêneo para o cruzamento com todos os genótipos maternos; (2) que os alelos de diferentes locos segregam independentemente; (3) que os locos não são afetados pela seleção ou mutação, entre o tempo de acasalamento e a análise; e (4) que os locos estão em equilíbrio de Hardy-Weinberg. Outras pressuposições como frequências intermediárias dos alelos têm também sido recomendada (GAIOTTO et al., 1997). Violações de algumas dessas pressuposições, principalmente a homogeneidade do conjunto de pólen, têm sido reportado por Gaiotto et al. (1997), Muchugi et al. (2008), Gusson et al. (2006), Muluvi et al. (2004) e Sebbenn et al. (1998).

Estimativa da taxa de cruzamento usando como artifício a frequência de heterozigotos, a frequência observada na geração materna e a frequência esperada na geração filial imediata é, talvez, apresentada de forma inédita neste trabalho, como forma de evitar-se modelos genético-estatísticos que impõem várias pressuposições, estimando-se a taxa de acasalamento diretamente das observações biológicas ou com um mínimo de pressuposições para a sua estimativa.

As estimativas obtidas com o método 1 apresentaram discrepâncias para algumas marcas de AFLP, apresentando valores acima de 1,0, e outras com valores entre 0,50 e 0,99, e a media de 1,063 indica alogamia completa em S. tuberosa Arruda, o que está em desacordo

Revista Árvore, Viçosa-MG, v.35, n.3, Edição Especial, p.691-697, 2011 
Tabela 1 - Frequência de ausência (0), teste qui-quadrado para segregação mendeliana 3:1, 1:1, 1:3 e estimativa para o alelo “q” materno (mãe) e filial subsequente (progênie) em duas populações de umbuzeiro avaliadas com duas combinações de iniciador AFLP. Petrolina, PE, 2008.

Table 1 - Absence frequency (0), chi-square test for the Mendelian segregation 3:1, 1:1 and 1:3, and estimates for the allele ' $q$ ' in the maternal and subsequent generation (progenies) in two umbu tree populations evaluated with two AFLP primers combinations. Petrolina, PE, 2008.

\begin{tabular}{|c|c|c|c|c|c|c|c|c|c|c|}
\hline \multirow[t]{3}{*}{ Marca AFLP } & \multicolumn{2}{|c|}{ Frequênciade zero } & \multicolumn{6}{|c|}{ Qui-quadrado } & \multicolumn{2}{|c|}{ Estimativade 'q' } \\
\hline & \multirow[b]{2}{*}{ Mãe } & \multirow[b]{2}{*}{ Progênie } & $3: 1$ & $1: 1$ & $1: 3$ & $3: 1$ & $1: 1$ & $1: 3$ & & \\
\hline & & & Mãe & Progênie & Mãe & Progênie & Mãe & Progênie & Mãe & Progênie \\
\hline AAA_CTG_1 & 0,131 & 0,215 & $5,5 *$ & $0,4^{\text {N.s. }}$ & $27,1 *$ & $16,2 *$ & $50,9 *$ & $38,1 *$ & 0,36 & 0,46 \\
\hline AAA_CTG_2 & 0,066 & 0,107 & $13,5^{*}$ & $8,1^{*}$ & $37,6 *$ & $30,8 *$ & $62,3 *$ & $55,0 *$ & 0,26 & 0,32 \\
\hline AAA_CTG_3 & 0,846 & 0,763 & $142,1^{*}$ & $105,4 *$ & $23,9 *$ & $13,8 *$ & $1,2^{\text {N.S. }}$ & $0,1^{\text {N.S. }}$ & 0,92 & 0,87 \\
\hline AAA_CTG_4 & 0,714 & 0,774 & $86,2 *$ & $109,9 *$ & $9,1^{*}$ & $15,0 *$ & $0,1^{\text {N.S. }}$ & $0,1^{\text {N.S. }}$ & 0,85 & 0,88 \\
\hline AAA_CTG_5 & 0,637 & 0,656 & $60,0 *$ & $65,9 *$ & $3,7^{\text {N.S. }}$ & $4,8 *$ & $1,6^{\text {N.S. }}$ & $1,1^{\text {N.S. }}$ & 0,80 & 0,81 \\
\hline AAA_CTG_6 & 0,494 & 0,451 & $23,9 *$ & $16,2^{*}$ & $0,1^{\text {N.S. }}$ & $0,4^{\text {N.s. }}$ & $8,7^{*}$ & $11,8 *$ & 0,70 & 0,67 \\
\hline AAA_CTC_1 & 0,311 & 0,543 & $1,4^{\mathrm{N} . \mathrm{S} .}$ & $34,2 *$ & $7,1^{*}$ & $0,3^{\text {N.s. }}$ & $25,6^{*}$ & $5,7 *$ & 0,56 & 0,73 \\
\hline AAA_CTC_2 & 0,456 & 0,500 & $16,9 *$ & $25,0 *$ & $0,3^{\text {N.S. }}$ & $0,0^{\text {N.S. }}$ & $11,5^{*}$ & $8,3 *$ & 0,67 & 0,71 \\
\hline AAA_CTC_3 & 0,622 & 0,351 & $55,4^{*}$ & $4,0 *$ & $2,9^{\text {N.s. }}$ & $4,4^{*}$ & $2,1^{\text {N.S. }}$ & $21,2 *$ & 0,79 & 0,59 \\
\hline AAA_CTC_4 & 0,600 & 0,404 & $49,0 *$ & $9,5 *$ & $2,0^{\text {N.S. }}$ & $1,8^{\text {N.S. }}$ & $3,0^{\text {N.S. }}$ & $15,9 *$ & 0,77 & 0,63 \\
\hline AAA_CTC_5 & 0,067 & 0,149 & $13,4^{*}$ & $4,0 *$ & $37,5 *$ & $24,6 *$ & $62,2 *$ & $48,1^{*}$ & 0,26 & 0,39 \\
\hline AAA_CTC_6 & 0,133 & 0,362 & $5,4 *$ & $4,9 *$ & $26,8 *$ & $3,8^{\text {N.S. }}$ & $50,7 *$ & $20,1 *$ & 0,36 & 0,60 \\
\hline AAA_CTC_7 & 0,767 & 0,745 & $106,7^{*}$ & $97,8 *$ & $14,2 *$ & $11,9 *$ & $0,1^{\text {N.S. }}$ & $0,1^{\text {N.S. }}$ & 0,87 & 0,86 \\
\hline AAA_CTC_8 & 0,211 & 0,245 & $0,6^{\text {N.s. }}$ & $0,1^{\text {N.s. }}$ & $16,6^{*}$ & $13,0 *$ & $38,7^{*}$ & $34,0 *$ & 0,46 & 0,49 \\
\hline AAA_CTC_9 & 0,433 & 0,500 & $13,4 *$ & $25,0 *$ & $0,8^{\text {N.S. }}$ & $0,0^{\text {N.S. }}$ & $13,3 *$ & $8,3 *$ & 0,66 & 0,71 \\
\hline AAA_CTC_10 & 0,233 & 0,340 & $0,1^{\text {N.s. }}$ & $3,2^{\text {N.S. }}$ & $14,2 *$ & $5,0 *$ & $35,5^{*}$ & $22,3 *$ & 0,48 & 0,58 \\
\hline
\end{tabular}

* e e $^{\text {N.s. }}$ significativo e não significativo a $5 \%$, pelo teste qui-quadrado.

Tabela 2 - Heterozigose observada (mãe), heterozigose esperada (progênie), coeficiente de endogamia e taxa de cruzamento em duas populações de umbuzeiro avaliadas com duas combinações de iniciador AFLP. Petrolina, PE, 2008.

Table 2 - Observed heterozygosity (mother), expected heterozygosity (progenies), inbreeding coefficient and out-crossing rates in two population of umbu tree evaluated with two AFLP primers combinations. Petrolina, PE, 2008.

\begin{tabular}{|c|c|c|c|c|}
\hline Marca AFLP & $\begin{array}{c}\text { Heterozigose } \\
\text { observada (mãe) }\end{array}$ & $\begin{array}{c}\text { Heterozigosees } \\
\text { perada (Progênie) }\end{array}$ & $\begin{array}{l}\text { Coeficiente de } \\
\text { endogamia }(\widehat{\mathrm{F}})\end{array}$ & $\begin{array}{c}\text { Taxa de } \\
\text { cruzamento }(\widehat{\mathrm{t}})\end{array}$ \\
\hline AAA_CTG_3 & 0,147 & 0,220 & 0,331 & 0,50 \\
\hline AAA_CTG_4 & 0,261 & 0,211 & $-0,238$ & 1,63 \\
\hline AAA_CTG_5 & 0,321 & 0,307 & $-0,045$ & 1,10 \\
\hline AAA_CTG_6 & 0,417 & 0,440 & 0,053 & 0,90 \\
\hline AAA_CTC_1 & 0,493 & 0,388 & $-0,271$ & 1,74 \\
\hline AAA_CTC_2 & 0,438 & 0,414 & $-0,059$ & 1,13 \\
\hline AAA_CTC_4 & 0,349 & 0,463 & 0,245 & 0,61 \\
\hline AAA_CTC_7 & 0,217 & 0,236 & 0,078 & 0,85 \\
\hline AAA_CTC_8 & 0,496 & 0,500 & 0,006 & 0,99 \\
\hline AAA_CTC_9 & 0,449 & 0,414 & $-0,086$ & 1,19 \\
\hline AAA_CTC_10 & 0,499 & 0,486 & $-0,027$ & 1,06 \\
\hline Média & 0,371 & 0,370 & $-0,001$ & 1,063 \\
\hline
\end{tabular}

com a estimativa obtida por Souza (2000). Para Moraes e Monteiro (2002), valores para a taxa de acasalamento acima de 1,0 são “biologicamente” inaceitáveis. Esses valores acima de 1 podem estar associados à seleção entre estádio de plântula e planta adulta, considerando-se que plântulas foram usadas para estimar a taxa de polinização cruzada no Método 1, o que pode inviabilizar esse procedimento (método 1) para estimar a taxa de acasalamento.

A estimativa obtida com o método 2 foi de 0,713 , que é próximo do valor de 0,74 estimado para o umbuzeiro 
com três sistemas de isoenzimas (SOUZA, 2000). Deve ser ressaltado que as frequências de óvulos e pólen para os 15 locos de AFLP foram iguais, indicando que não houve violação do modelo de acasalamento misto. Diante do exposto, deve-se considerar o umbuzeiro como uma espécie de acasalamento livre, com taxa de autofecundação de 0,287.

Spondias tuberosa é espécie andromonoica, possuindo flores hermafroditas e masculinas em uma mesma inflorescência, com a antese tendo início às 5 h e duração de dois dias em flores hermafroditas e de um dia nas masculinas (NADIA et al., 2007). A taxa intermediária de autofertilização estimada pelo método multilocos está de acordo com as características florais da espécie, que de certa forma favorece a autopolinização.

Como revisado por Muchugi et al. (2008), espécies arbóreas tropicais têm apresentado predominância da polinização cruzada, o que para esses autores explica a alta variabilidade genética encontrada dentro de populações das arbóreas tropicais. Stacy et al. (1996) determinaram com cinco sistemas isoenzimáticos que Spondias mombin, espécie do mesmo gênero do umbuzeiro, é completamente alógama, ou seja, apresenta $100 \%$ de taxa de polinização cruzada.

Os resultados das análises com as estimativas multilocos sugerem a necessidade da aplicação de modelos biométricos que levem em consideração os desvios de livre acasalamento nas estimativas dos parâmetros genéticos e a necessidade de amostras amplas para preservar a variabilidade genética, como enfatizado por Freitas et al. (2004) para Myracrodruon urundeuva.

Os níveis de heterozigosidade elevados detectados neste estudo são altamente relevantes para a conservação in situ, visto o grande número de novas recombinações genotípicas possíveis de ocorrer, mantendo, assim, o potencial evolutivo da espécie, as adaptações às prováveis mudanças ambientais e a colonização de novas áreas.

\section{CONCLUSÃO}

5.1. As estimativas da taxa de cruzamento $(\widehat{t})$ com a frequência de heterozigotos observada nas mães e a frequência esperada nos descendentes variaram de 1,74 a 0,50, com média de 1,063, indicando que o método não foi apropriado para estimar $\hat{\mathrm{t}}$.
5.2. A taxa de cruzamento multilocos $\left(\widehat{t}_{m}\right)$ obtida pelo software MLTR foi de 0,719 ( \pm 0,000), que é próxima de estimativa prévia com isoenzimas em outras populações da espécie

5.3. S. tuberosa Arruda é predominantemente de polinização cruzada, sendo necessários ajustes nos modelos biométricos para estimar parâmetros genéticos, bem como a necessidade de amostras amplas para preservar a variabilidade genética da espécie

\section{AGRADECIMENTOS}

Ao Banco do Nordeste do Brasil, pelo apoio financeiro.

\section{REFERENCIAS}

CRESTE, S.; TULMANN NETO, A.; FIGUEIRA, A. Detection of single sequence repeat polymorphisms in denaturing polyacrylamide sequencing gels by silver staining. Plant Molecular Biology Reporter, v.9, p.299-306, 2001.

DOYLE, J. J.; DOYLE, J. L. Isolation of plant DNA from fresh tissue. Focus, v.12, n.1, p.13-15, 1990.

FALCONER, D. S.; MACKAY, T. F. C.

Introduction to quantitative genetics. Essex: Longman Scientific and Technical, 1996. 464p.

FREITAS, M. L. M. et al. Mating system of a population of Myracrodruon urundeuva F.F. \& M.F. Genetic and Molecular Biology, v.27, n.3, p.425-431, 2004.

GAIOTTO, F. A.; BRAMUCCI, M.;

GRATTAPAGLIA, D. Estimation of outcrossing rate in a breeding population of Eucalyptus urophylla with dominant RAPD and AFLP markers. Theoretical and Applied Genetics, v.95, n.5/6, p.842-849, 1997.

GIUDICE NETO, J. D.; SEBBENN, A. M.; KAGEYAMA, P. Y. Diversidade genética de uma população "ex situ” de Caesalpinia echinata Lam. Scientia Florestalis, v.69, p.125-133, 2005.

GUSSON, E.; SEBBENN, A. M.; KAGEYAMA, P. Y. Sistema de reprodução em populações de eschweilera ovata (Cambess.) Miers. Revista Árvore, v.30, n.4, p.491-502, 2006. 
HAMRICK, J. L. \& GODT, M. J. W. Allozyme diversity in plant species. In: BROWN, A. H. D. et al. (Eds) Plant population genetics, breeding and genetic resources. Sunderland: Sinauer Associates, 1989. p.43-63.

MORAES, P. L. R.; MONTEIRO, R. Taxas de cruzamento em uma população natural de Cryptocarya moschata Nees (Lauraceae). Biota Neotropica, v.2, n.2, 2002. http:// www.biotaneotropica.org.br/v2n2/pt/ abstract?article+BN01102022002

MORAES, M. L. T.; KAGEYAMA, P. Y.; SEBBENN, A. M. Diversidade e estrutura genética espacial em duas populações de Myracrodruon urundeuva Fr. All. sob diferentes condições antrópicas. Revista Árvore, v.29, n.2, p.281-289, 2005.

MUCHUGI, A. et al. Estimation of out-crossing rate in a natural breeding population of Warburgia ugandensis using AFLP marker. African Journal of Biotechnology, v.7, n.2, p.139-146, 2008.

MULUVI, G. M. et al. Estimates of outcrossing rates in Moringa oleifera using Amplified fragment length polymorphism (AFLP). African Journal of Biotechnology, v.3, n.2, p.146-151, 2004.

NADIA, T. L.; MACHADO, I. C.; LOPES, A. V. Polinização de Spondias tuberosa Arruda (Anacardiaceae) e análise da partilha de polinizadores com Ziziphus joazeiro Mart. (Rhamnaceae), espécies frutíferas e endêmicas da caatinga. Revista Brasileira de Botânica, v.30, n.1, p.89-100, 2007.

PAIVA, J. R.; KAGEYAMA, P. Y.; VENCOVSKY, R. Genetics of rubber tree (Hevea brasiliensis (Willd. ex Adr. de Juss.) Mull Arg.). 2. Mating system. Silvae Genética, v. 43, n.5/6, p.373-376, 1994.

PASTEUR, N. et al. Practical isozyme genetics. New York: Haisted Press, 1988. 215p.

PRADO, D. E.; GIBBS, P. E. Patterns of species distribution in the dry seasonal forests of South America. Ann Missouri Botanical Garden, v.80, p.902-927, 1993.
RIBEIRO, H. L. C. et al. Transferência de primers SSRs da mangueira (Mangifera indica) para o umbuzeiro (Spondias tuberosa Arr.). In: JORNADA DE INICIAÇÃO CIENTIFICA DA EMBRAPA SEMI-ÁRIDO, 3., 2008, Petrolina. Anais... Petrolina: Embrapa Semi-Árido, 2008. p.149-154 (Embrapa Semi-Árido, 210)

RITLAND, K. Extensions of models for the estimation of mating systems using $n$ independent loci. Heredity, n.88, p.221-228, 2002.

RUVOLO-TAKASUSUKI, M.C.; MACHADO, M.F.P.S.; HÉLIO CONTE, H. Esterase-3 polymorphism in the sugarcane borer Diatraea saccharalis (Lepidoptera, Pyralidae).

Genetics and Molecular Biology, v.25, n.1, p.61-64, 2002.

SANTOS, C. A. F. In situ evaluation of fruit yield and estimation of repeatability coefficient for major fruit traits of umbu tree (Spondias tuberosa (Anacardiaceae) in the semi-arid region of Brazil.

Genetic Resources and Crop

Evolution, n.46, p.455-460, 1999.

SANTOS, C. A. F.; RODRIGUES, M. A.; ZUCCHI, M. I. Variabilidade genética do umbuzeiro no Semi-Árido brasileiro, por meio de marcadores AFLP. Pesquisa Agropecuária Brasileira, v.43, p.1037-1043, 2008.

SEBBENN, A. M.; KAGEYAMA, P. Y.; VENCOVSKY, R. Variabilidade genética, sistema reprodutivo e estrutura genética espacial em Genipa americana L. através de marcadores isoenzimáticos. Scientia Forestalis, v.53, n.1, p.15-30, 1998.

SOUZA, J. C. Variabilidade genética e sistema de cruzamento em populações naturais de umbuzeiro (Spondias tuberosa Arr. Cam.), 2000. 86f. Tese (Doutorado em Genética e Melhoramento) - Universidade Federal de Viçosa, Viçosa, MG, 2000.

STACY, E. A. et al. Pollen dispersal in low-density populations of three neotropical tree species.

The American naturalist, v.148, n.2, p.275298, 1996. 
